\title{
Substitution of pure fruit juice for fruit and sugar-sweetened beverages and cardiometabolic risk in European Prospective Investigation into Cancer and Nutrition (EPIC)-NL: a prospective cohort study
}

\author{
Floor R Scheffers ${ }^{1,2,3, *}$ (0), Jolanda MA Boer ${ }^{1}$, Alet H Wijga ${ }^{1}$, Yvonne T van der Schouw², \\ Henriëtte A Smit ${ }^{2}$ and WM Monique Verschuren ${ }^{1,2}$ \\ ${ }^{1}$ Center for Nutrition, Prevention, and Health Services, National Institute for Public Health and the Environment (RIVM), \\ Bilthoven 3720 BA, The Netherlands: 2Julius Center for Health Sciences and Primary Care, University Medical Center \\ Utrecht, Utrecht University, Utrecht, The Netherlands: ${ }^{3}$ Faculty of Health, Nutrition and Sport, The Hague University of \\ Applied Sciences, The Hague, The Netherlands
}

Submitted 19 June 2020: Final revision received 18 February 2021: Accepted 24 February 2021: First published online 1 March 2021

\begin{abstract}
Objective: Dietary guidelines on pure fruit juice differ between countries regarding the question whether pure fruit juice (without added sugars) is an acceptable substitute for fruit or should be avoided because of its comparable sugar content with that of sugar-sweetened beverages (SSB). We modelled whether substituting pure fruit juice for fruit or SSB was associated with cardiometabolic risk.

Design: Prospective cohort study.

Setting: Based on a validated FFQ at baseline, we calculated the relative contribution of pure fruit juice to total consumption of fruit and pure fruit juice $\left(\frac{\text { pure fruit juice }(\mathrm{g} / \mathrm{day})}{\text { fruit }+ \text { pure fruit juice }(\mathrm{g} / \mathrm{day})}\right)$ and to total consumption of SSB and pure fruit juice $\left(\frac{\text { pure fruit juice }(\mathrm{g} / \text { day })}{\mathrm{sSBs}+\text { pure fruit juice }(\mathrm{g} / \text { day })}\right)$. In multivariate analyses (Cox regression), we assessed associations with incidence of type 2 diabetes, CVD, CHD and stroke after an average follow-up of 14.6 years.

Participants: About 35000 participants from the EPIC-NL study, aged 20-70 years at enrolment.

Results: Substitution of pure fruit juice for SSB was associated with lower risk of all endpoints. For type 2 diabetes and CHD, for example, drinking 75-100 \% (as compared with $0-<25 \%$ ) of total SSB + pure fruit juice as pure fruit juice showed hazard ratio $(95 \% \mathrm{CI})$ of 0.74 (95\% CI $0.64,0.85)$ and 0.85 (95\% CI $0.76,0.96)$, respectively. Substitution of pure fruit juice for fruit was not associated with the risk of type 2 diabetes, CVD, CHD and stroke.

Conclusions: Substituting pure fruit juice for SSB was associated with lower cardiometabolic risk, whereas substituting pure fruit juice for fruit was not associated with cardiometabolic risk.
\end{abstract}

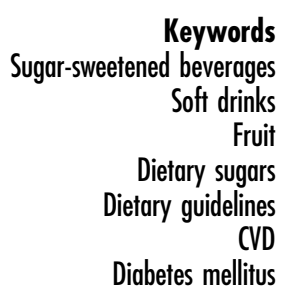

Dietary guidelines differ in their classification of pure fruit juice $^{(1)}$. Many countries state that whole fruit can be (partially) replaced by pure fruit juice, while a few countries group pure fruit juice with sugar-sweetened beverages (SSB) because of the comparable sugar content ${ }^{(2,3)}$. For this reason, the Dutch dietary guidelines state that consumption of pure fruit juice should be restricted to a minimum ${ }^{(2)}$. Pure fruit juice is defined as $100 \%$ fruit juice that can be freshly squeezed or bottled juice and never contains added sugars,

artificial sweeteners, flavourings, preservatives or colourings ${ }^{(4)}$. It therefore differs from SSB. However, pure fruit juice also differs from whole fruits because pure fruit juice contains less dietary fibre and vitamin $\mathrm{C}^{(5)}$. The conflicting dietary guidelines on pure fruit juice emphasise the importance of studying the question whether pure fruit juice is an acceptable alternative for whole fruits or whether its health effects are more comparable with those of SSB like soft drinks and fruit juices with added sugars. Most previous

*Corresponding author: Email floor.scheffers@rivm.nl

(C) The Author(s), 2021. Published by Cambridge University Press on behalf of The Nutrition Society. This is an Open Access article, distributed under the terms of the Creative Commons Attribution-NonCommercial-NoDerivatives licence (http://creativecommons.org/licenses/by-nc-nd/4.0/), which permits non-commercial re-use, distribution, and reproduction in any medium, provided the original work is unaltered and is properly cited. The written permission of Cambridge University Press must be obtained for commercial re-use or in order to create a derivative work. 
epidemiological research investigated associations of pure fruit juice ${ }^{(6,7)}$, whole fruits ${ }^{(8-14)}$ or $\operatorname{SSB}^{(15,16)}$ with cardiometabolic risk separately. However, epidemiological research on the possible effect of substituting pure fruit juice for whole fruits or SSB and cardiometabolic risk is scarce $^{(17,18)}$. Substitution analyses enable us to analyse the effect of replacing part of the fruit consumption by pure fruit juice (while total fruit + pure fruit juice consumption remains constant) and the effect of replacing part of the SSB consumption by pure fruit juice (while total SSB + pure fruit juice consumption remains constant). Therefore, we investigated whether substituting pure fruit juice for fruit and SSB was associated with cardiometabolic risk. We hypothesised that substituting pure fruit juice for fruit is not associated with cardiometabolic risk, whereas substituting pure fruit juice for SSB is associated with lower cardiometabolic risk. This hypothesis is based on previous epidemiological evidence for an association between fruit consumption and lower cardiometabolic risk $^{(6,8-14)}$, an association between SSB consumption and higher cardiometabolic risk $^{(15,16)}$ and no or an inverse association between pure fruit juice consumption and cardiometabolic risk ${ }^{(6,7,15)}$.

\section{Methods}

\section{Study population}

The EPIC-NL study consists of the two Dutch cohorts (Prospect and MORGEN) that contribute to the European Prospective Investigation into Cancer and Nutrition (EPIC). These cohorts were set up simultaneously in 1993-1997 and merged into one Dutch EPIC cohort. The MORGEN cohort consists of 22654 men and women aged 20-65 years selected from random samples of the Dutch population in three towns in the Netherlands (Amsterdam, Doetinchem and Maastricht). The Prospect cohort consists of 17357 women aged $49-70$ years, who participated in the national breast cancer screening programme and were living in the Dutch town Utrecht or its surroundings. The EPIC-NL study design has been described elsewhere ${ }^{(19)}$. All participants gave written informed consent before they were included in the study.

For the present study, we excluded participants who withdrew permission for inclusion in the study $(n 1)$, with missing FFQ ( $n$ 218) and extremely low or high reported energy intake (i.e. those in the lowest or highest $0.5 \%$ of the ratio of energy intake over BMR) ( $n$ 390). After these exclusions, we used separate exclusion criteria for the analyses on the different endpoints, that is, type 2 diabetes and CVD. For the analyses on diabetes risk, we further excluded participants with missing follow-up ( $n$ 1738), participants with prevalent diabetes at baseline, nonverified incident diabetes and unknown types of incident diabetes ( $n$ 1241), and participants with missing data on possible confounders and intermediates ( $n$ 276). After these exclusions, 36147 participants remained for the analyses on diabetes risk. For the analyses on CVD risk, we excluded participants with missing follow-up ( $n$ 1729), with prevalent CVD at baseline ( $n$ 1192), with prevalent diabetes mellitus at baseline ( $n$ 643) or missing data on possible confounders and intermediates ( $n$ 1306). After these exclusions, 34532 participants remained in the analyses on CVD risk (Fig. 1).

\section{Exposure assessment}

Dietary intake was obtained from a self-administered FFQ containing questions on the average consumption of 178 food items during the year preceding enrolment (between 1993 and 1997). The FFQ has been validated against the mean of twelve 24-h recalls. For fruit consumption, the relative validity for ranking of the subjects, expressed as Spearman's correlation coefficients between the FFQ and the mean of twelve 24-h recalls, was 0.68 in men and 0.56 in women ${ }^{(20)}$. Participants indicated their consumption of pure fruit juice and SSB in glasses per day, per week, per month, per year or as never. The prespecified choices for fruit juice were apple juice, orange/grape juice and other fruit juice. For apple juice and orange/grapefruit juice, a glass size of $150 \mathrm{ml}$ was assumed. For other fruit juice, a glass size of $100 \mathrm{ml}$ was assumed. These portion sizes were based on data from the Dutch National Food Consumption Survey 1993/1994. The prespecified choices for SSB were cola, other sugary soft drinks (including fruit juices with added sugar) and fruit syrups (i.e. fruit drink concentrate with added sugar). For SSB, a glass size of $150 \mathrm{ml}$ was used. Fruit consumption (excluding products like apple sauce) in winter and fruit consumption in summer were assessed with separate questions. The prespecified choices for summer fruits were apple/pear, citrus fruit, banana, strawberry, grapes, peach, cherries, kiwi, melon, 'other, namely....', while the prespecified choices for winter fruits were apple/ pear, citrus fruit, banana, kiwi, 'other, namely ..... We used standard portion sizes from the Dutch Food Composition Database $(\mathrm{NEVO})^{(21)}$ to convert portions into grams of fruit (Appendix B).

\section{Assessment of type 2 diabetes}

A two-step approach was used for the identification and validation of potential type 2 diabetes cases. For the identification of potential cases, information was obtained from follow-up questionnaires and through linkage with the hospital discharge register, covering all general and university hospitals and most specialised hospitals in the Netherlands. These data were linked to the EPIC-NL cohort based on information on date of birth, postal code, sex and general practitioner, using a validated probabilistic $\operatorname{method}^{(22)}$. In the hospital discharge register, all diagnoses were coded according to the International Classification of Diseases, Ninth Revision, Clinical Modification (ICD-9-CM). Diabetes was based on code 250 and underlying codes. 


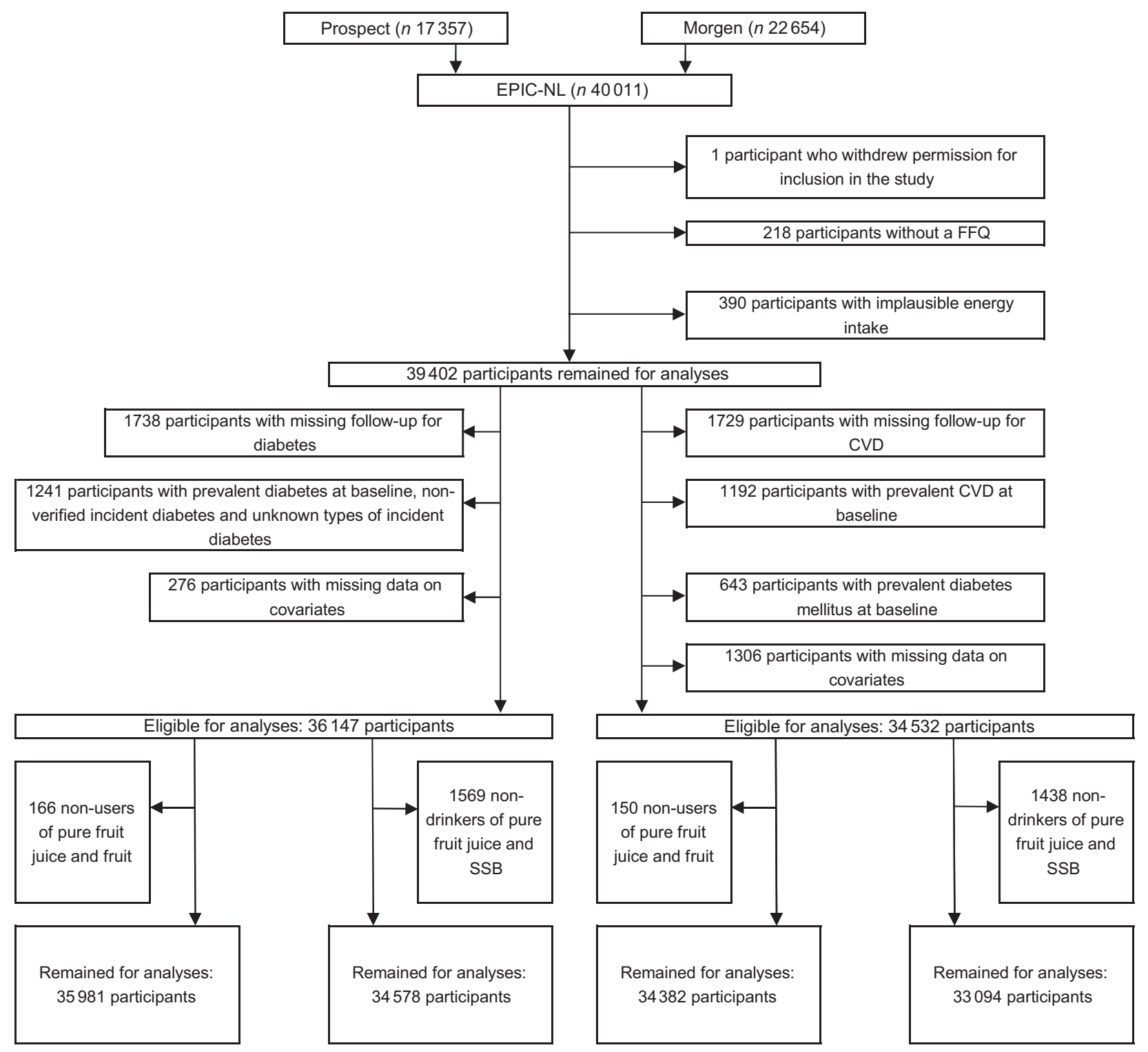

Fig. 1 Flow chart of participants excluded from the study

The follow-up questionnaires collected data on selfreported diabetes and were sent out with intervals of 3-5 years (years 1998-2002 questionnaire 1, 20032007 questionnaire 2 and 2011-2012 questionnaire 3). Prospect participants additionally received a urinary glucose strip test with the first questionnaire. They were asked to self-report whether the strip had turned purple after $10 \mathrm{~s}$, for detection of glycosuria. For the main analyses, we only used verified diabetes cases. All potential type 2 diabetes cases up to 2006 were validated by consulting the general practitioner or the pharmacist ${ }^{(23)}$. For all potential cases identified after 2006, only the general practitioner was used as verification source. The verification source provided the diagnosis year, and we set the diagnosis date for all identified cases at 1 January, in the year of diagnosis. Follow-up was complete until 31 December 2010.

\section{Assessment of CVD}

In addition to the hospital discharge diagnoses described above, data on vital status were obtained from the municipal population register. For those who died, data on the cause of death were obtained from Statistics Netherlands. Data until 1996 were coded according to ICD-9, and data after 1996 were coded according to ICD-10 (Appendix A). Follow-up was complete until 31 December 2010. Outcomes for the present study were CVD, CHD and stroke, either fatal or nonfatal. The first event was used as outcome.

\section{Confounders and intermediates}

Educational level was defined as low (primary education, lower vocational education, advanced elementary education), intermediate (intermediate vocational education, completion of first 3 years of higher general secondary education) and high (completed higher general secondary 
education, higher vocational education and university). Family history of diabetes was classified as none, one parent, both parents and unknown. Cigarette, cigar or pipe smoking was classified as current, former or never. Physical activity was assessed using the validated ${ }^{(24)}$ EPIC physical activity questionnaire and classified according to the Cambridge Physical Activity Index into the dichotomous variable (moderately) active/(moderately) inactive ${ }^{(25)}$. Physical activity was not assessed with the EPIC questionnaire in the first year (1993) of the MORGEN study. Therefore, $14 \%$ of the EPIC-NL cohort had no data on Cambridge Physical Activity Index. These missing values were imputed using single imputation (SPSS MVA procedure) ${ }^{(26)}$. The Dutch Healthy Diet index 2015 (DHD15-index) was used as a measure of diet quality. This index is based on the adherence to the Dutch dietary guidelines of $2015^{(2)}$ and consists of the following fifteen components: vegetables, fruit, wholegrain products, legumes, nuts, dairy, fish, tea, fats and oils, filtered coffee, red meat, processed meat, sugarsweetened beverages, alcohol and salt. For all these components, a score between 0 (no adherence) and 10 (complete adherence) is assigned, which results in a total score ranging from 0 to 150 points $^{(27)}$. In the EPIC-FFQ, no distinction was made between types of coffee (filtered or unfiltered). Therefore, the component score for coffee was not included in the DHD15-index we used. Fruit and sugar-containing beverages (which included SSB and pure fruit juice) were also not included because these were the exposure variables of interest in our study. Consequently, our DHD15-index was the sum of twelve components ranging from 0 (no adherence) to 120 (complete adherence). Energy intake was calculated from the FFQ in kcal. BMI was calculated as weight (measured in light clothing, with empty pockets and no shoes) divided by height squared $\left(\mathrm{kg} / \mathrm{m}^{2}\right)$. Waist circumference was measured in $\mathrm{cm}$. Systolic blood pressure was calculated as the mean of two measurements, and total cholesterol was measured in mmol using enzymatic methods.

\section{Statistical analyses}

All analyses were performed using SAS, version 9.4 (SAS Institute). Characteristics of the study population were described using descriptive statistics. There are different methods available to perform substitution analyses. We followed the method developed by van den Brandt ${ }^{(28)}$ who studied the association between substituting tea for coffee and overall and cause-specific mortality risk.

To estimate the association of substituting pure fruit juice for fruit with cardiometabolic risk, we calculated the relative contribution (\%) of pure fruit juice to total consumption of fruit and pure fruit juice:

$$
\frac{\text { Pure fruit juice }(\mathrm{g} / \mathrm{d})}{\text { Fruit }+ \text { pure fruit juice }(\mathrm{g} / \mathrm{d})}
$$

To estimate the association of substituting pure fruit juice for SSB with cardiometabolic risk, we calculated the relative contribution (\%) of pure fruit juice to total consumption of SSB and pure fruit juice:

$$
\frac{\text { Pure fruit juice }(\mathrm{g} / \mathrm{d})}{\mathrm{SSB}+\text { pure fruit juice }(\mathrm{g} / \mathrm{d})}
$$

These relative contributions were categorised into three and four categories, respectively, and used in multivariate analyses, while controlling for total consumption of pure fruit juice $+\mathrm{SSB}$ or total consumption of pure fruit juice + fruit consumption (to keep total consumption constant). We used this method ${ }^{(28)}$ because we studied only one substitution at a time in our statistical models, that is, pure fruit juice for solid food (whole fruits) or for liquid food (SSB). Furthermore, standard substitution analyses, estimating the substitution effect as the difference in effect measure (i.e. $\beta_{\text {pure fruit juice }}-\beta_{\mathrm{SSB}}$ ), assume a linear relationship, whereas the associations of pure fruit juice and SSB consumption with cardiometabolic risk in our study were nonlinear. For analyses of substituting pure fruit juice for fruit, participants who consumed no pure fruit juice and no fruit were excluded, while for analyses of substituting pure fruit juice for SSB, non-drinkers of both pure fruit juice and SSB were excluded (Fig. 1). Pooled hazard ratio (HR) were estimated using stratified Cox models assuming different baseline hazards for the two cohorts. The proportional hazard assumption was fulfilled according to Schoenfeld residuals. Consideration of potential confounders was based on a difference $>10 \%$ in effect estimate between crude and adjusted models and/or theoretical considerations. For both the analyses on diabetes risk and the risk of CVD, the first model was adjusted for total consumption of pure fruit juice $+\mathrm{SSB}$ or total consumption of pure fruit juice + fruit consumption (to keep total consumption constant), age and sex. The second model was adjusted for total consumption of pure fruit juice + SSB or total consumption of pure fruit juice + fruit consumption, age, sex, educational level, physical activity, smoking, family history of diabetes, DHD15-index, alcohol consumption, coffee consumption and fruit consumption (for analyses of substituting pure fruit juice for SSB) or SSB (for analyses of substituting pure fruit juice for fruit). Additionally, in the third model, energy intake was added to elucidate the role of this potential intermediate factor in the association with both diabetes and CVD risk. For the analyses on diabetes risk, the fourth model extended model 2 with BMI and waist circumference (but not energy intake) to explore the role of these potential intermediate factors. For the analyses on the risk of CVD, the fourth model extended model 2 with BMI, waist circumference, systolic blood pressure and total cholesterol (but not energy intake) as potential intermediate factors.

\section{Sensitivity analyses}

Verification information was not available for 490 of the 1967 potential type 2 diabetes cases, mainly because the 
general practitioner could not be traced or did not respond. Sensitivity analyses were performed including these participants as diabetes cases.

\section{Results}

\section{Descriptive statistics}

Baseline characteristics of the diabetes data sets and CVD data sets largely overlap. Therefore, we present the baseline characteristics of the two diabetes data sets because these contain the largest number of participants. Around $25 \%$ of our study population were men, and the average age at baseline was 49 years $(\mathrm{SD}=12)$. Median total pure fruit juice + fruit consumption was $240 \mathrm{~g} / \mathrm{d}(\mathrm{IQR}=231)$.

Median total pure fruit juice + SSB consumption was $133 \mathrm{~g} / \mathrm{d}$ (IQR = 166). Participants drinking relatively high amounts of pure fruit juice while eating low amounts of fruit were more often men, were younger, were more likely to smoke and drank more alcohol than participants with a low contribution of pure fruit juice to total consumption of fruit + pure fruit juice (Table 1). Participants drinking relatively high amounts of pure fruit juice but low amounts of SSB were more often women, were older, were less likely to smoke and drank less alcohol than participants with a low contribution of pure fruit juice to the total consumption of SSB + pure fruit juice (Table 2).

\section{Substitution of pure fruit juice for fruit}

In the analyses on substitution of pure fruit juice for fruit, 1469 verified incident cases of type 2 diabetes and 3769 CVD events, including 2113 CHD events and 759 stroke events, were included that were documented after a mean follow-up of $14 \cdot 6$ years (range: $10-17 \cdot 0$ years).

\section{Type 2 diabetes}

For the substitution of pure fruit juice for fruit, no associations were found with the risk of type 2 diabetes after adjustment for possible confounders. Compared with those drinking $0-25 \%$ as pure fruit juice and eating $75-100 \%$ as fruit, HR (95\% CI) in the other categories (increasing pure fruit juice and decreasing fruit consumption) were 0.92 (95\% CI $0.81,1.04$ ) for those drinking $25-<50 \%$ as pure fruit juice of total fruit + pure fruit juice and 1.04 (95\% CI $0.91,1.19)$ for those drinking $50-100 \%$ as pure fruit juice of total fruit + pure fruit juice (Table 3 ; model 2 ).

\section{CVD}

For the substitution of pure fruit juice for fruit, no associations were found with the risk of CVD after adjustment for possible confounders. Compared with those drinking 0$25 \%$ as pure fruit juice and eating $75-100 \%$ as fruit, HR $(95 \% \mathrm{CI})$ in the other categories (increasing pure fruit juice and decreasing fruit) were 0.94 (95\% CI $0.87,1.02)$ for those drinking $25-<50 \%$ as pure fruit juice of total fruit + pure fruit juice and 1.06 (95\% CI 0.97, 1.15) for those drinking $50-100 \%$ as pure fruit juice of total fruit + pure fruit juice (Table 4, model 2). For CHD and stroke, also no statistically significant associations were found (Table 4 , model 2).

\section{Substitution of pure fruit juice for sugar-sweetened beverages}

In the analyses for substitution of pure fruit juice for SSB, 1397 verified incident cases of type 2 diabetes and 3515 CVD events, including 1979 CHD events and 704 stroke events, were included that were documented after a mean follow-up of $14 \cdot 6$ years (range $0-18 \cdot 0$ ).

\section{Type 2 diabetes}

Substitution of pure fruit juice for SSB was associated with a lower risk of type 2 diabetes, after adjustment for total pure fruit juice + SSB consumption age, sex, educational level, physical activity, smoking, family history of diabetes, DHD15-index, alcohol, coffee and fruit. Compared with those drinking $0-25 \%$ as pure fruit juice and $75-100 \%$ as $\mathrm{SSB}$, all other categories (increasing pure fruit juice and decreasing SSB) showed a lower risk of type 2 diabetes. The lowest HR was observed for those drinking 75$100 \%$ of total SSB + pure fruit juice as pure fruit juice (HR: 0.74; $95 \%$ CI 0.64, 0.85) (Table 5; model 2).

\section{CVD}

Substitution of pure fruit juice for SSB was also associated with a lower risk of CVD, CHD and stroke after adjustment for possible confounders. Consumption of $50-<75 \%$ of total SSB + pure fruit juice as pure fruit juice was significantly associated with a reduced risk of CVD (HR: 0.91; $95 \%$ CI $0.82,1.00)$ and stroke (HR: 0.80; $95 \%$ CI 0.64, 0.99) compared with those drinking $0-25 \%$ as pure fruit juice and $75-100 \%$ as SSB (Table 6, model 2). Consuming $75-100 \%$ of total SSB + pure fruit juice as pure fruit juice was associated with a reduced risk of CHD (HR: 0.85; $95 \%$ CI 0.76, 0.96) (Table 6, model 2).

\section{Role of intermediate factors}

For the substitution of pure fruit juice for fruit, additional inclusion of possible intermediate factors yielded similar results for all endpoints (Tables 3 and 5, models 3 and 4). Additional inclusion of possible intermediate factors for the substitution of pure fruit juice for SSB also yielded similar results for CVD, CHD and stroke (Table 6, models 3 and 4). However, for type 2 diabetes, additional inclusion of BMI and waist circumference, but not additional adjustment for energy intake, slightly attenuated the results, but the trend was still significant, as was the effect for the group drinking $75-100 \%$ of total SSB + pure fruit juice as pure fruit juice (HR: 0.83; $95 \%$ CI 0.72, 0.96) (Table 5, model 4).

\section{Sensitivity analyses}

Inclusion of unverified potential diabetes cases yielded similar results for both the substitution of pure fruit juice for fruit and for the substitution of pure fruit juice for SSB 
Table 1 Baseline characteristics by contribution of pure fruit juice to total fruit + pure fruit juice

\begin{tabular}{|c|c|c|c|c|c|c|c|c|}
\hline & \multicolumn{8}{|c|}{ Contribution of pure fruit juice to total consumption of fruit + pure fruit juice (median) } \\
\hline & \multicolumn{2}{|c|}{ All participants } & \multicolumn{2}{|c|}{$\begin{array}{c}0-<25 \%(n 18683) \\
(7 \%)\end{array}$} & \multicolumn{2}{|c|}{$\begin{array}{c}25-<50 \%(n 9755) \\
(35 \%)\end{array}$} & \multicolumn{2}{|c|}{$\begin{array}{c}50-100 \%(n 7543) \\
(61 \%)\end{array}$} \\
\hline & $\%$ & $n$ & $\%$ & $n$ & $\%$ & $n$ & $\%$ & $n$ \\
\hline \multicolumn{9}{|l|}{ Cohort } \\
\hline Prospect & 43.6 & 15684 & $48 \cdot 2$ & 9011 & $44 \cdot 8$ & 4371 & 30.5 & 2302 \\
\hline MORGEN & $56 \cdot 4$ & 20297 & $51 \cdot 8$ & 9672 & $55 \cdot 2$ & 5384 & 69.5 & 5241 \\
\hline \multicolumn{9}{|l|}{ Sex } \\
\hline Male & $25 \cdot 4$ & 9128 & $24 \cdot 0$ & 4489 & $22 \cdot 1$ & 2156 & 32.9 & 2483 \\
\hline \multicolumn{9}{|l|}{ Education level* } \\
\hline Low & $57 \cdot 5$ & 20688 & $59 \cdot 9$ & 11183 & $54 \cdot 2$ & 5285 & $56 \cdot 0$ & 4220 \\
\hline Intermediate & 21.9 & 7896 & $20 \cdot 4$ & 3812 & $22 \cdot 5$ & 2191 & $25 \cdot 1$ & 1893 \\
\hline High & $20 \cdot 6$ & 7397 & $19 \cdot 7$ & 3688 & 23.4 & 2279 & $19 \cdot 0$ & 1430 \\
\hline \multicolumn{9}{|l|}{ Family history of diabetes } \\
\hline None & $76 \cdot 7$ & 27604 & $76 \cdot 0$ & 14195 & 77.4 & 7552 & $77 \cdot 7$ & 5857 \\
\hline One parent & $17 \cdot 0$ & 33730 & $17 \cdot 9$ & 3336 & $16 \cdot 5$ & 1605 & $15 \cdot 7$ & 1185 \\
\hline Both parents & 0.9 & 34054 & 1.0 & 180 & 0.9 & 92 & 0.7 & 52 \\
\hline Unknown & 5.4 & 1927 & $5 \cdot 2$ & 972 & $5 \cdot 2$ & 506 & $6 \cdot 0$ & 449 \\
\hline \multicolumn{9}{|l|}{ Smoking status } \\
\hline Never & $38 \cdot 2$ & 13759 & $37 \cdot 1$ & 6929 & $41 \cdot 2$ & 4014 & $37 \cdot 3$ & 2861 \\
\hline Former & 31.4 & 11302 & $34 \cdot 1$ & 6372 & $31 \cdot 2$ & 3039 & $25 \cdot 1$ & 1891 \\
\hline Current & $30 \cdot 4$ & 10920 & $28 \cdot 8$ & 5382 & $27 \cdot 7$ & 2702 & $37 \cdot 6$ & 2836 \\
\hline \multicolumn{9}{|l|}{ Physical activity } \\
\hline (Moderately) Inactive & 31.9 & 11470 & $32 \cdot 0$ & 5983 & $30 \cdot 7$ & 2996 & $33 \cdot 0$ & 2491 \\
\hline (Moderately) Active & $68 \cdot 1$ & 24511 & $68 \cdot 0$ & 12700 & $69 \cdot 3$ & 6759 & $67 \cdot 0$ & 5052 \\
\hline \multicolumn{9}{|l|}{ Alcohol intake } \\
\hline Never & 0.4 & 156 & 0.5 & 95 & 0.3 & 31 & 0.4 & 30 \\
\hline$<10$ ethanol $(\mathrm{g} / \mathrm{d})$ & $62 \cdot 7$ & 22573 & $63 \cdot 1$ & 11790 & $62 \cdot 8$ & 6126 & $61 \cdot 7$ & 4657 \\
\hline $10-<20$ ethanol $(g / d)$ & $16 \cdot 5$ & 5937 & $16 \cdot 7$ & 3120 & $17 \cdot 0$ & 1655 & $15 \cdot 4$ & 1162 \\
\hline $20-<30$ ethanol $(\mathrm{g} / \mathrm{d})$ & 9.9 & 3556 & $9 \cdot 9$ & 1852 & $9 \cdot 7$ & 946 & $10 \cdot 1$ & 758 \\
\hline \multirow[t]{2}{*}{$\geq 30$ ethanol $(\mathrm{g} / \mathrm{d})$} & $10 \cdot 5$ & 3759 & $9 \cdot 8$ & 1826 & $10 \cdot 2$ & 997 & $12 \cdot 4$ & 936 \\
\hline & Mean & SD & Mean & SD & Mean & SD & Mean & SD \\
\hline Age (years) & $49 \cdot 1$ & 11.9 & $50 \cdot 8$ & $11 \cdot 0$ & $49 \cdot 0$ & $12 \cdot 0$ & $45 \cdot 4$ & $13 \cdot 0$ \\
\hline BMI & $25 \cdot 6$ & 3.9 & $25 \cdot 7$ & 3.9 & $25 \cdot 5$ & 3.9 & $25 \cdot 5$ & $4 \cdot 1$ \\
\hline Waist circumference $(\mathrm{cm})$ & $85 \cdot 0$ & $11 \cdot 3$ & $85 \cdot 2$ & $11 \cdot 2$ & $84 \cdot 3$ & $11 \cdot 1$ & $85 \cdot 3$ & 11.9 \\
\hline Diastolic blood pressure $(\mathrm{mmHg})$ & $77 \cdot 7$ & $10 \cdot 6$ & $78 \cdot 1$ & $10 \cdot 4$ & $77 \cdot 4$ & $10 \cdot 6$ & $77 \cdot 2$ & $11 \cdot 0$ \\
\hline Systolic blood pressure $(\mathrm{mmHg})$ & $126 \cdot 0$ & $18 \cdot 7$ & $127 \cdot 0$ & $18 \cdot 8$ & $125 \cdot 4$ & $18 \cdot 6$ & $124 \cdot 1$ & $18 \cdot 5$ \\
\hline Total-/HDL-cholesterol (mmol/l) & 5.54 & 1.08 & $5 \cdot 60$ & 1.07 & 5.53 & 1.09 & 5.40 & $1 \cdot 11$ \\
\hline HDL-cholesterol (mmol/l) & 1.47 & 0.42 & 1.48 & 0.42 & 1.49 & 0.41 & 1.41 & 0.40 \\
\hline Ratio total:HDL-cholesterol (mmol/l) & 4.06 & 1.42 & $4 \cdot 07$ & 1.41 & $4 \cdot 00$ & 1.39 & $4 \cdot 13$ & 1.49 \\
\hline \multirow[t]{2}{*}{ DHD15-index } & $53 \cdot 3$ & $12 \cdot 3$ & $53 \cdot 3$ & $12 \cdot 4$ & 54.5 & $12 \cdot 2$ & $51 \cdot 8$ & $12 \cdot 2$ \\
\hline & Median & IQR & Median & IQR & Median & IQR & Median & IQR \\
\hline $\begin{array}{l}\text { Total pure fruit juice and fruit } \\
\text { consumption }(\mathrm{g} / \mathrm{d})\end{array}$ & 240 & 231 & 225 & 194 & 295 & 219 & 241 & 193 \\
\hline Sugar-sweetened beverages $(\mathrm{g} / \mathrm{d}) \dagger$ & 43 & 104 & 35 & 90 & 52 & 102 & 69 & 140 \\
\hline Dairy beverages $(\mathrm{g} / \mathrm{d})$ & 171 & 316 & 151 & 277 & 200 & 354 & 193 & 361 \\
\hline Coffee $(g / d)$ & 450 & 433 & 450 & 450 & 375 & 375 & 438 & 455 \\
\hline Total energy intake $(\mathrm{kcal} / \mathrm{d})$ & 1956 & 747 & 1895 & 718 & 1979 & 705 & 2081 & 827 \\
\hline
\end{tabular}

DHD15-index, Dutch Healthy Diet index 2015.

“Education level categorised as 'low' (primary education, lower vocational education, advanced elementary education), 'intermediate' (intermediate vocational education, completion of first 3 years of higher general secondary education, and 'high' (completed higher general secondary education, higher vocational education and university). †Sugar-sweetened beverages included sugar-containing soft drinks and fruit syrups.

(see additional files; see online supplementary material, Supplemental Table 1 and 2).

\section{Discussion}

This study showed that substituting pure fruit juice for fruit was not associated with the risk of type 2 diabetes, CVD,
CHD and stroke, whereas substituting pure fruit juice for SSB was associated with lower risk of type 2 diabetes, CVD, CHD and stroke.

\section{Results of otber studies}

We found one study that investigated substituting pure fruit juice for SSB in relation to CHD risk ${ }^{(17)}$. This meta-analysis, 
Table 2 Baseline characteristics by contribution of pure fruit juice to total sugar-sweetened beverages (SSB) + pure fruit juice

\begin{tabular}{|c|c|c|c|c|c|c|c|c|c|c|}
\hline & \multicolumn{10}{|c|}{ Contribution of pure fruit juice to total consumption of SSB + pure fruit juice (median) } \\
\hline & \multicolumn{2}{|c|}{ All participants } & \multicolumn{2}{|c|}{$\begin{array}{c}0-<25 \% \\
(n 10615)(5 \%)\end{array}$} & \multicolumn{2}{|c|}{$\begin{array}{c}25-<50 \% \\
(n 6480)(38 \%)\end{array}$} & \multicolumn{2}{|c|}{$\begin{array}{c}50-<75 \% \\
(n 7509)(62 \%)\end{array}$} & \multicolumn{2}{|c|}{$\begin{array}{c}75-100 \% \\
(n 9974)(95 \%)\end{array}$} \\
\hline & $\%$ & $n$ & $\%$ & $n$ & $\%$ & $n$ & $\%$ & $n$ & $\%$ & $n$ \\
\hline \multicolumn{11}{|l|}{ Cohort } \\
\hline Prospect & $42 \cdot 6$ & 14740 & $30 \cdot 7$ & 3260 & $35 \cdot 0$ & 2270 & 44.6 & 3349 & $58 \cdot 8$ & 5861 \\
\hline MORGEN & 57.4 & 19838 & $69 \cdot 3$ & 7355 & $65 \cdot 0$ & 4210 & 55.4 & 4160 & $41 \cdot 2$ & 4113 \\
\hline \multicolumn{11}{|l|}{ Sex } \\
\hline Male & $25 \cdot 8$ & 8919 & $37 \cdot 8$ & 4014 & $29 \cdot 1$ & 1886 & $21 \cdot 2$ & 1592 & $14 \cdot 3$ & 1427 \\
\hline \multicolumn{11}{|l|}{ Education level* } \\
\hline Low & $56 \cdot 7$ & 19609 & $60 \cdot 0$ & 6371 & $51 \cdot 6$ & 3345 & $54 \cdot 7$ & 4104 & $58 \cdot 0$ & 5789 \\
\hline Intermediate & $22 \cdot 4$ & 7736 & $24 \cdot 6$ & 2607 & $26 \cdot 2$ & 1698 & $21 \cdot 6$ & 1620 & $18 \cdot 2$ & 1811 \\
\hline High & $20 \cdot 9$ & 7233 & $15 \cdot 4$ & 1637 & $22 \cdot 2$ & 1437 & $23 \cdot 8$ & 1785 & $23 \cdot 8$ & 2374 \\
\hline \multicolumn{11}{|l|}{ Family history of diabetes } \\
\hline None & $76 \cdot 9$ & 26590 & $76 \cdot 7$ & 8145 & 78.2 & 5067 & $77 \cdot 3$ & 5807 & $75 \cdot 9$ & 7571 \\
\hline One parent & $16 \cdot 9$ & 5832 & $16 \cdot 3$ & 1734 & $16 \cdot 0$ & 1035 & $17 \cdot 2$ & 1294 & $17 \cdot 7$ & 1769 \\
\hline Both parents & 0.9 & 314 & 0.9 & 98 & 0.8 & 50 & 0.8 & 60 & $1 \cdot 1$ & 106 \\
\hline Unknown & $5 \cdot 3$ & 1842 & $6 \cdot 0$ & 638 & $5 \cdot 1$ & 328 & $4 \cdot 6$ & 348 & $5 \cdot 3$ & 528 \\
\hline \multicolumn{11}{|l|}{ Smoking status } \\
\hline Never & 38.5 & 13320 & 31.9 & 3382 & 39.7 & 2570 & 41.9 & 3148 & $42 \cdot 3$ & 4220 \\
\hline Former & 31.4 & 10847 & $30 \cdot 5$ & 3242 & $30 \cdot 3$ & 1963 & 31.5 & 2368 & $32 \cdot 8$ & 3274 \\
\hline Current & $30 \cdot 1$ & 10411 & 37.6 & 3991 & $30 \cdot 1$ & 1947 & $26 \cdot 5$ & 1993 & 24.9 & 2480 \\
\hline \multicolumn{11}{|l|}{ Physical activity } \\
\hline (Moderately) Inactive & $31 \cdot 6$ & 10933 & 33.6 & 3569 & $29 \cdot 8$ & 1930 & $30 \cdot 2$ & 2267 & $31 \cdot 8$ & 3167 \\
\hline (Moderately) Active & $68 \cdot 4$ & 23645 & $66 \cdot 4$ & 7046 & $70 \cdot 2$ & 4550 & $69 \cdot 8$ & 5242 & $68 \cdot 3$ & 6807 \\
\hline \multicolumn{11}{|l|}{ Alcohol intake } \\
\hline Never & 0.4 & 127 & 0.5 & 54 & 0.3 & 16 & 0.3 & 20 & 0.4 & 37 \\
\hline$<10$ ethanol $(\mathrm{g} / \mathrm{d})$ & $63 \cdot 0$ & 21791 & $61 \cdot 8$ & 6559 & 62.5 & 4048 & $64 \cdot 0$ & 4805 & $64 \cdot 0$ & 6379 \\
\hline $10-<20$ ethanol $(\mathrm{g} / \mathrm{d})$ & $16 \cdot 5$ & 5714 & $16 \cdot 2$ & 1723 & $18 \cdot 3$ & 1185 & $16 \cdot 4$ & 1231 & $15 \cdot 8$ & 1575 \\
\hline $20-<30$ ethanol $(\mathrm{g} / \mathrm{d})$ & $9 \cdot 8$ & 3382 & $9 \cdot 7$ & 1029 & $9 \cdot 3$ & 604 & $9 \cdot 7$ & 731 & $10 \cdot 2$ & 1018 \\
\hline \multirow[t]{2}{*}{$\geq 30$ ethanol $(g / d)$} & $10 \cdot 3$ & 3564 & $11 \cdot 8$ & 1250 & $9 \cdot 7$ & 627 & $9 \cdot 6$ & 722 & $9 \cdot 7$ & 965 \\
\hline & Mean & SD & Mean & SD & Mean & SD & Mean & SD & Mean & SD \\
\hline Age (years) & $48 \cdot 8$ & $11 \cdot 9$ & $46 \cdot 2$ & $12 \cdot 2$ & $46 \cdot 6$ & $12 \cdot 2$ & $49 \cdot 1$ & $11 \cdot 7$ & $52 \cdot 8$ & $10 \cdot 4$ \\
\hline BMI & $25 \cdot 6$ & 3.9 & $25 \cdot 9$ & $4 \cdot 1$ & 25.5 & 3.9 & 25.5 & 3.9 & 25.4 & 3.9 \\
\hline Waist circumference (cm) & 84.9 & 11.4 & $86 \cdot 7$ & $12 \cdot 0$ & $84 \cdot 8$ & 11.4 & 84.4 & $10 \cdot 9$ & $83 \cdot 6$ & $10 \cdot 7$ \\
\hline Diastolic blood pressure (mmHg) & $77 \cdot 7$ & $10 \cdot 6$ & $78 \cdot 0$ & $10 \cdot 5$ & $77 \cdot 2$ & $10 \cdot 5$ & $77 \cdot 7$ & $10 \cdot 7$ & $77 \cdot 7$ & $10 \cdot 7$ \\
\hline Systolic blood pressure (mmHg) & $125 \cdot 7$ & $18 \cdot 6$ & $124 \cdot 9$ & $18 \cdot 1$ & $124 \cdot 2$ & $18 \cdot 0$ & $125 \cdot 9$ & $18 \cdot 8$ & $127 \cdot 4$ & $19 \cdot 3$ \\
\hline Total-/HDL-cholesterol (mmol/l) & 5.53 & 1.08 & 5.46 & $1 \cdot 10$ & 5.42 & 1.08 & 5.54 & 1.08 & $5 \cdot 67$ & 1.06 \\
\hline HDL-cholesterol (mmol//) & 1.47 & 0.42 & $1 \cdot 39$ & 0.41 & 1.44 & 0.41 & 1.49 & 0.41 & 1.54 & 0.42 \\
\hline Ratio total:HDL-cholesterol (mmol/l) & 4.06 & 1.43 & $4 \cdot 24$ & 1.52 & 4.05 & 1.43 & 3.99 & 1.37 & 3.93 & 1.33 \\
\hline \multirow[t]{2}{*}{ DHD15-index } & $53 \cdot 4$ & $12 \cdot 3$ & $50 \cdot 7$ & $12 \cdot 5$ & $53 \cdot 3$ & $12 \cdot 0$ & 54.5 & $12 \cdot 1$ & $55 \cdot 4$ & $12 \cdot 0$ \\
\hline & Median & IQR & Median & IQR & Median & IQR & Median & IQR & Median & IQR \\
\hline $\begin{array}{l}\text { Total pure fruit juice and SSB } \\
\text { consumption }(\mathrm{g} / \mathrm{d})\end{array}$ & 133 & 166 & 124 & 198 & 145 & 200 & 158 & 153 & 133 & 110 \\
\hline Sugar-sweetened beverages $(\mathrm{g} / \mathrm{d}) \dagger$ & 49 & 107 & 110 & 177 & 92 & 117 & 54 & 63 & 5 & 20 \\
\hline Dairy beverages (g/d) & 176 & 329 & 147 & 339 & 200 & 352 & 200 & 351 & 171 & 281 \\
\hline Coffee $(g / d)$ & 450 & 433 & 450 & 450 & 450 & 413 & 450 & 346 & 375 & 375 \\
\hline Total energy intake $(\mathrm{kcal} / \mathrm{d})$ & 1968 & 746 & 2047 & 879 & 2043 & 791 & 1972 & 695 & 1857 & 617 \\
\hline
\end{tabular}

DHD15-index, Dutch Healthy Diet index 2015.

‘Education level categorised as 'low' (primary education, lower vocational education, advanced elementary education), 'intermediate' (intermediate vocational education completion of first 3 years of higher general secondary education) and 'high' (completed higher general secondary education, higher vocational education and university). †Sugar-sweetened beverages included sugar-containing soft drinks and fruit syrups.

in which data from six prospective studies were pooled, showed that substituting one serving $(355 \mathrm{ml})$ pure fruit juice for one serving SSB was not associated with CHD risk (HR: 0.96; $95 \%$ CI 0.86, 1.08). We found similar HR for those drinking $25-<50 \%$ and $50-<75 \%$ pure fruit juice of total SSB + pure fruit juice. Another study, a prospective case-cohort study which combined data from eight European cohorts, including EPIC-NL, found no association of substituting $250 \mathrm{~g} / \mathrm{d}$ pure fruit juice for the same quantity of SSB with the risk of type 2 diabetes (HR: 0.89; $95 \%$ CI 0.74, $1.07)^{(18)}$. However, this association was adjusted for energy intake, BMI and waist circumference. We did not include these possible intermediates in our main model (model 2) because inclusion of intermediate factors may lead to overadjustment. Our models specifically addressing the roles of these potential intermediates showed that the model in which BMI 
Table 3 Diabetes risk by contribution of pure fruit juice to total fruit and pure fruit juice

\begin{tabular}{|c|c|c|c|c|c|c|}
\hline & \multicolumn{6}{|c|}{ Contribution of pure fruit juice to total consumption of fruit + pure fruit juice (median) } \\
\hline & \multirow{2}{*}{$\frac{0-<25 \%(7 \%)}{H R}$} & \multicolumn{2}{|c|}{$25-<50 \%(35 \%)$} & \multicolumn{2}{|c|}{$50-100 \%(61 \%)$} & \multirow[b]{2}{*}{$P$-trend } \\
\hline & & HR & $95 \% \mathrm{Cl}$ & $\mathrm{HR}$ & $95 \% \mathrm{Cl}$ & \\
\hline All participants, $n$ & 18683 & & & & & \\
\hline Type 2 diabetes, $n$ & 823 & & & & & \\
\hline Mean follow-up period (years) & $14 \cdot 6$ & & & & & \\
\hline Model $1^{*}$ & 1.00 & 0.90 & $0.80,1.02$ & $1 \cdot 11$ & $0.97,1 \cdot 28$ & 0.48 \\
\hline Model $2 \dagger$ & 1.00 & 0.92 & $0.81,1.04$ & 1.04 & $0.91,1.19$ & 0.85 \\
\hline Model 3‡ & 1.00 & 0.93 & $0.82,1.05$ & 1.05 & $0.92,1.20$ & 0.65 \\
\hline Model $4 \S$ & 1.00 & 0.92 & $0.81,1.05$ & 0.98 & $0 \cdot 86,1 \cdot 13$ & $0 \cdot 71$ \\
\hline
\end{tabular}

HR, hazard ratio; DHD15-index, Dutch Healthy Diet index 2015.

${ }^{*}$ Adjusted for total pure fruit juice + fruit consumption, age and sex.

†Adjusted for total pure fruit juice + fruit consumption, age, sex, educational level, physical activity, smoking, family history of diabetes, DHD15-index, coffee, sugar-sweetened beverages.

$\ddagger$ Adjusted for total pure fruit juice + fruit consumption, age, sex, educational level, physical activity, smoking, family history of diabetes, DHD15-index, coffee, sugar-sweetened beverages and energy intake.

§Adjusted for total pure fruit juice + fruit consumption, age, sex, educational level, physical activity, smoking, family history of diabetes, DHD15-index, coffee, sugar-sweetened beverages, BMI and waist circumference.

Table 4 CVD risk by contribution of pure fruit juice to total fruit and pure fruit juice

\begin{tabular}{|c|c|c|c|c|c|c|}
\hline & \multicolumn{6}{|c|}{ Contribution of pure fruit juice to total consumption of fruit + pure fruit juice (median) } \\
\hline & \multirow{2}{*}{$\frac{0-<25 \%(7 \%)}{H R}$} & \multicolumn{2}{|c|}{$25-<50 \%(35 \%)$} & \multicolumn{2}{|c|}{$50-100 \%(61 \%)$} & \multirow[b]{2}{*}{$P$-trend } \\
\hline & & $\mathrm{HR}$ & $95 \% \mathrm{Cl}$ & HR & $95 \% \mathrm{Cl}$ & \\
\hline All participants, $n$ & 17770 & & 9340 & & & \\
\hline CVD, $n$ & 2107 & & 905 & & & \\
\hline Mean follow-up period (years) & 14.4 & & 14.5 & & & \\
\hline Model $1^{*}$ & 1.00 & 0.93 & $0.86,1.00$ & 1.13 & $1.04,1.22$ & 0.76 \\
\hline Model $2 \dagger$ & 1.00 & 0.94 & $0.87,1.02$ & 1.06 & $0.97,1.15$ & 0.86 \\
\hline Model 3‡ & 1.00 & 0.94 & $0.87,1.02$ & 1.06 & $0.98,1.16$ & 0.96 \\
\hline Model $4 \S$ & 1.00 & 0.94 & $0.87,1.02$ & 1.05 & $0.96,1.14$ & 0.98 \\
\hline $\mathrm{CHD}, n$ & 1188 & & 493 & & & \\
\hline Mean follow-up period (years) & $14 \cdot 6$ & & 14.7 & & & \\
\hline Model $1^{\star}$ & 1.00 & 0.89 & $0.80,0.99$ & $1 \cdot 11$ & $0.99,1.24$ & 0.76 \\
\hline Model $2 \dagger$ & 1.00 & 0.91 & $0.82,1.01$ & 1.05 & $0.94,1.18$ & 0.59 \\
\hline Model 3‡ & 1.00 & 0.91 & $0.82,1.01$ & 1.05 & $0.94,1.18$ & 0.96 \\
\hline Model $4 \S$ & 1.00 & 0.91 & $0.81,1.01$ & 1.04 & $0.93,1.16$ & 0.94 \\
\hline Stroke, $n$ & 434 & & 180 & & & \\
\hline Mean follow-up period (years) & 14.9 & & 14.9 & & & \\
\hline Model $1^{*}$ & 1.00 & 0.90 & $0.76,1.08$ & $1 \cdot 11$ & $0.92,1.34$ & 0.92 \\
\hline Model $2 \dagger$ & 1.00 & 0.90 & $0.75,1.08$ & 1.02 & $0.84,1.24$ & 0.57 \\
\hline Model 3‡ & 1.00 & 0.90 & $0.76,1.08$ & 1.02 & $0.84,1.24$ & 0.63 \\
\hline Model 4§ & 1.00 & 0.90 & $0.75,1.08$ & 1.01 & $0.83,1.22$ & 0.50 \\
\hline
\end{tabular}

HR, hazard ratio; DHD15-index, Dutch Healthy Diet index 2015

${ }^{*}$ Adjusted for total pure fruit juice + fruit consumption, age and sex.

†Adjusted for total pure fruit juice + fruit consumption, age, sex, educational level, physical activity, smoking, family history of diabetes, DHD15-index, coffee, sugar-sweetened beverages.

$\ddagger$ Adjusted for total pure fruit juice + fruit consumption, age, sex, educational level, physical activity, smoking, family history of diabetes, DHD15-index, coffee, sugar-sweetened beverages and energy intake.

§Adjusted for total pure fruit juice + fruit consumption, age, sex, educational level, physical activity, smoking, family history of diabetes, DHD15-index, coffee, sugar-sweetened beverages, BMI, waist circumference, systolic blood pressure and total cholesterol.

and waist circumference were added (model 4, Table 5), all associations attenuated and became more similar to the association found by Imamure et al (HR: 0.89; $95 \%$ CI $0 \cdot 74,1 \cdot 07)^{(18)}$.

\section{Interpretation of the results of the present study}

In 2015, the WHO published a guideline that recommends adults and children to reduce daily intake of free sugars to $<10 \%$ of total energy intake. In this guideline, free sugars refer to both sugars added to foods and sugars naturally present in, for example, pure fruit juices, but not to sugars in fresh fruit ${ }^{(29)}$. Based on the comparable sugar content and the expected adverse health effects of sugar intake, some countries like the Netherlands and New Zealand group pure fruit juice with SSB in their dietary guidelines ${ }^{(2,3)}$. However, most countries state in their dietary guidelines that pure fruit juice can (partially) replace whole fruits. In contrast to $\mathrm{SSB}$, pure fruit juice 
Table 5 Diabetes risk by contribution of pure fruit juice to total sugar-sweetened beverages (SSB) and pure fruit juice

\begin{tabular}{|c|c|c|c|c|c|c|c|c|}
\hline & \multicolumn{8}{|c|}{ Contribution of pure fruit juice to total consumption of SSB + pure fruit juice (median) } \\
\hline & \multirow{2}{*}{$\frac{0-<25 \%(5 \%)}{H R}$} & \multicolumn{2}{|c|}{$25-<50 \%(38 \%)$} & \multicolumn{2}{|c|}{$50-<75 \%(62 \%)$} & \multicolumn{2}{|c|}{$75-100 \%(95 \%)$} & \multirow[b]{2}{*}{$P$-trend } \\
\hline & & $\mathrm{HR}$ & $95 \% \mathrm{Cl}$ & HR & $95 \% \mathrm{Cl}$ & $\mathrm{HR}$ & $95 \% \mathrm{Cl}$ & \\
\hline All participants, $n$ & 10615 & & 480 & & 7509 & & 9974 & \\
\hline Type 2 diabetes, $n$ & 477 & & 221 & & 293 & & 406 & \\
\hline Mean follow-up period (years) & $14 \cdot 6$ & & 14.7 & & 14.7 & & $14 \cdot 6$ & \\
\hline Model $1^{*}$ & 1.00 & 0.73 & $0.62,0.85$ & 0.73 & $0.63,0.85$ & 0.66 & $0.57,0.75$ & $<0.0001$ \\
\hline Model $2 \dagger$ & 1.00 & 0.80 & $0.68,0.93$ & 0.82 & $0.71,0.95$ & 0.74 & $0.64,0.85$ & $<0.0001$ \\
\hline Model $3 \ddagger$ & 1.00 & 0.81 & $0.69,0.95$ & 0.83 & $0.72,0.97$ & 0.75 & $0.65,0.86$ & $<0.0001$ \\
\hline Model $4 \S$ & 1.00 & 0.86 & $0.73,1.01$ & 0.90 & $0.78,1.05$ & 0.83 & $0.72,0.96$ & 0.01 \\
\hline
\end{tabular}

HR, hazard ratio; DHD15-index, Dutch Healthy Diet index 2015.

${ }^{*}$ Adjusted for total pure fruit juice + SSB consumption, age and sex.

†Adjusted for total pure fruit juice + SSB consumption, age, sex, educational level, physical activity, smoking, family history of diabetes, DHD15-index, alcohol, coffee and fruit. $\ddagger$ Adjusted for total pure fruit juice + SSB consumption, age, sex, educational level, physical activity, smoking, family history of diabetes, DHD15-index, alcohol, coffee, fruit and energy intake.

§Adjusted for total pure fruit juice + SSB consumption, age, sex, educational level, physical activity, smoking, family history of diabetes, DHD15-index, alcohol, coffee, fruit, $\mathrm{BMI}$ and waist circumference.

Table 6 CVD risk by contribution of pure fruit juice to total sugar-sweetened beverages (SSB) and pure fruit juice

\begin{tabular}{|c|c|c|c|c|c|c|c|c|}
\hline & \multicolumn{8}{|c|}{ Contribution of pure fruit juice to total consumption of SSB + pure fruit juice (median) } \\
\hline & \multirow{2}{*}{$\frac{0-<25 \%(5 \%)}{H R}$} & \multicolumn{2}{|c|}{$25-<50 \%(38 \%)$} & \multicolumn{2}{|c|}{$50-<75 \%(62 \%)$} & \multicolumn{2}{|c|}{$75-100 \%(94 \%)$} & \multirow[b]{2}{*}{$P$-trend } \\
\hline & & HR & $95 \% \mathrm{Cl}$ & HR & $95 \% \mathrm{Cl}$ & HR & $95 \% \mathrm{Cl}$ & \\
\hline All participants, $n$ & 10177 & & 6242 & & 7219 & & 9456 & \\
\hline CVD, $n$ & 1128 & & 610 & & 707 & & 1070 & \\
\hline Mean follow-up period (years) & 14.4 & & 14.4 & & 14.5 & & $14 \cdot 3$ & \\
\hline Model $1^{\star}$ & 1.00 & 0.90 & $0.81,0.99$ & 0.81 & $0.73,0.89$ & 0.82 & $0.76,0.90$ & $<0.0001$ \\
\hline Model $2 \dagger$ & 1.00 & 0.99 & $0.89,1.09$ & 0.91 & $0.82,1.00$ & 0.92 & $0.85,1.01$ & 0.01 \\
\hline Model $3 \ddagger$ & 1.00 & 0.99 & $0.90,1.10$ & 0.91 & $0.83,1.00$ & 0.93 & $0.85,1.01$ & 0.02 \\
\hline Model $4 \S$ & 1.00 & 1.01 & $0.92,1.12$ & 0.93 & $0.84,1.02$ & 0.95 & $0.87,1.04$ & 0.07 \\
\hline $\mathrm{CHD}, n$ & 666 & & 349 & & 414 & & 550 & \\
\hline Mean follow-up period (years) & $14 \cdot 6$ & & 14.6 & & $14 \cdot 7$ & & $14 \cdot 6$ & \\
\hline Model $1^{*}$ & 1.00 & 0.89 & $0.78,1.01$ & 0.84 & $0.74,0.95$ & 0.76 & $0.68,0.86$ & $<0.0001$ \\
\hline Model $2 \dagger$ & 1.00 & 0.98 & $0.86,1.12$ & 0.94 & $0.83,1.07$ & 0.85 & $0.76,0.96$ & 0.003 \\
\hline Model 3‡ & 1.00 & 0.98 & $0.86,1.12$ & 0.94 & $0.83,1.07$ & 0.85 & $0.76,0.96$ & 0.003 \\
\hline Model $4 \S$ & 1.00 & 1.01 & $0.88,1.15$ & 0.96 & $0.85,1.09$ & 0.88 & $0.78,0.99$ & 0.02 \\
\hline Stroke, $n$ & 217 & & 117 & & 133 & & 237 & \\
\hline Mean follow-up period (years) & 14.9 & & 14.9 & & $15 \cdot 0$ & & $14 \cdot 8$ & \\
\hline Model $1^{*}$ & 1.00 & 0.85 & $0.68,1.06$ & 0.71 & $0.57,0.89$ & 0.82 & $0.68,0.99$ & 0.02 \\
\hline Model $2 \dagger$ & 1.00 & 0.92 & $0.74,1.16$ & 0.80 & $0.64,0.99$ & 0.91 & $0.75,1.11$ & 0.24 \\
\hline Model $3 \ddagger$ & 1.00 & 0.93 & $0.74,1.17$ & 0.80 & $0.64,1.00$ & 0.92 & $0.75,1.11$ & 0.25 \\
\hline Model 4§ & 1.00 & 0.94 & $0.75,1.19$ & 0.81 & $0.65,1.01$ & 0.93 & $0.77,1.13$ & 0.35 \\
\hline
\end{tabular}

HR, hazard ratio; DHD15-index, Dutch Healthy Diet index 2015.

${ }^{\star}$ Adjusted for total pure fruit juice + SSB consumption, age and sex.

†Adjusted for total pure fruit juice + SSB consumption, age, sex, educational level, physical activity, smoking, family history of diabetes, DHD15-index, coffee, fruit.

†Adjusted for total pure fruit juice + SSB consumption, age, sex, educational level, physical activity, smoking, family history of diabetes, DHD15-index, coffee, fruit and energy intake.

§Adjusted for total pure fruit juice + SSB consumption, age, sex, educational level, physical activity, smoking, family history of diabetes, DHD15-index, coffee, fruit, BMI, waist circumference, systolic blood pressure and total cholesterol.

and whole fruit contain polyphenols which might be associated with reduced cardiometabolic risk $^{(30-34)}$. This may be an important explanation of our finding why substituting pure fruit juice for fruit was not associated with cardiometabolic risk, whereas substituting pure fruit juice for SSB was associated with lower cardiometabolic risk. Specifically for type 2 diabetes, differences in the glycaemic index between SSB (medium glycaemic index) and pure fruit juice (low glycaemic index) could additionally explain why substituting pure fruit juice for SSB is associated with a lower diabetes risk ${ }^{(35-37)}$. In contrast, our study showed that substitution of pure fruit juice for fruit was not associated with diabetes risk, which might be explained by the comparable glycaemic index for whole fruit and pure fruit juice.

\section{Strengths and limitations}

Strengths of this study include the large sample size, prospective design, long follow-up period and the availability of many relevant confounders. A validated self-reported 
FFQ with separate items for consumption of pure fruit juice and SSB made it possible to distinguish these beverages from each other. This study has also some limitations typical for observational research. Residual confounding due to unmeasured or changed confounders or intermediates during follow-up cannot be ruled out. For example, we did not have data on income and were therefore not able to include this, in addition to educational level, as an indicator of socio-economic status. Furthermore, data on pure fruit juice consumption were collected at baseline and may have changed during follow-up. Last, reporting of nonpure fruit juice as pure fruit juice cannot be ruled out. In addition, we did not study the association of pure fruit juice consumption with dental caries, although this is an important adverse effect of pure fruit juice consumption ${ }^{(29)}$.

\section{Conclusions}

Based on this study, we found that pure fruit juice is not comparable to SSB in relation to cardiometabolic risk, despite their similar sugar content. Furthermore, we found that pure fruit juice is not different from fruit in relation to cardiometabolic risk. However, more research is needed to further investigate which dietary guidelines for pure fruit juice are most appropriate.

\section{Acknowledgements}

Acknowledgements: We thank Statistics Netherlands and the PHARMO Institute for follow-up data on causes of death, diabetes incidence and CVD. Financial support: This work is part of the research programme Doctoral Grant for Teachers with project number 023.005.010, which is financed by the Netherlands Organisation for Scientific Research (NWO). The funders had no role in study design, data collection and analysis, decision to publish or preparation of the manuscript. The EPIC-NL study was funded by 'Europe against Cancer' Programme of the European Commission (DG SANCO); the Dutch Ministry of Health, Welfare and Sports (VWS); the Netherlands Organisation for Health Research and Development (ZonMW) and the World Cancer Research Fund (WCRF). None of the study sponsors had a role in study design, data collection and analysis, decision to publish or preparation of the manuscript. Conflict of interest: None. Authorship: The authors' responsibilities were as follows: F.R.S. was responsible for the statistical analysis, interpretation of the results and the draft of the manuscript. A.H.W., J.A.M.B. and H.A.S. contributed to the conception and design of the current study. A.H.W., J.M.A.B., H.A.S. and W.M.M.V. contributed to the interpretation of the results and critical revision of initial drafts. All authors were responsible for critical revision of the manuscript, and they all read and approved the final manuscript. Ethics of buman subject participation: This study was conducted according to the guidelines laid down in the Declaration of Helsinki, and all procedures involving study participants were approved by the institutional board of the University Medical Center Utrecht (Prospect) and the Medical Ethical Committee of TNO Nutrition and Food Research (MORGEN). Written informed consent was obtained from all subjects.

\section{Supplementary material}

For supplementary material accompanying this paper visit https://doi.org/10.1017/S1368980021000914

\section{References}

1. Herforth A, Arimond M, Álvarez-Sánchez C et al. (2019) A global review of food-based dietary guidelines. Adv Nutr 10, 590-605.

2. Health Council of the Netherlands (2015) Dutch Dietary Guidelines 2015. The Hague: Health Council of the Netherlands.

3. Ministry of Health (2015) Eating and Activity Guidelines for New Zealand Adults. Wellington: Ministry of Health.

4. Warenwetbesluit vruchtensappen (2012) Fruit juices commodities Act 2012. https://wetten.overheid.nl/BWBR0032162/ 2016-02-19 (accessed October 2020).

5. Clemens R, Drewnowski A, Ferruzzi MG et al. (2015) Squeezing fact from fiction about $100 \%$ fruit juice. $A d v$ Nutr 6, 236s-243s.

6. Scheffers FR, Boer JMA, Verschuren WMM et al. (2019) Pure fruit juice and fruit consumption and the risk of CVD: the European Prospective Investigation into Cancer and Nutrition-Netherlands (EPIC-NL) study. Br J Nutr 121, 351-359.

7. Scheffers FR, Wijga AH, Verschuren WMM et al. (2020) Pure fruit juice, fruit consumption are not associated with incidence of type 2 diabetes after adjustment for overall dietary quality in the European Prospective Investigation into Cancer, Nutrition-Netherlands (EPIC-NL) study. J Nutr 150, 1470-1477.

8. Dauchet L, Amouyel P \& Dallongeville J (2005) Fruit and vegetable consumption and risk of stroke: a meta-analysis of cohort studies. Neurology 65, 1193-1197.

9. Dauchet L, Amouyel P, Hercberg S et al. (2006) Fruit and vegetable consumption and risk of coronary heart disease: a meta-analysis of cohort studies. J Nutr 136, 2588-2593.

10. Miller V, Mente A, Dehghan M et al. (2017) Fruit, vegetable, legume intake, cardiovascular disease, deaths in 18 countries (PURE): a prospective cohort study. Lancet 390, 2037-2049.

11. Wang X, Ouyang Y, Liu J et al. (2014) Fruit and vegetable consumption and mortality from all causes, cardiovascular disease, and cancer: systematic review and dose-response meta-analysis of prospective cohort studies. BMJ349, g4490.

12. Li M, Fan Y, Zhang X et al. (2014) Fruit and vegetable intake and risk of type 2 diabetes mellitus: meta-analysis of prospective cohort studies. BMJ Open 4, e005497.

13. Wu Y, Zhang D, Jiang X et al. (2015) Fruit and vegetable consumption and risk of type 2 diabetes mellitus: a doseresponse meta-analysis of prospective cohort studies. Nutr Metab Cardiovasc Dis 25, 140-147.

14. Li S, Miao S, Huang Y et al. (2015) Fruit intake decreases risk of incident type 2 diabetes: an updated meta-analysis. Endocrine 48, 454-460.

15. Neuenschwander M, Ballon A, Weber KS et al. (2019) Role of diet in type 2 diabetes incidence: umbrella review of 
meta-analyses of prospective observational studies. BMJ 366, 12368

16. Malik VS \& Hu FB (2019) Sugar-sweetened beverages and cardiometabolic health: an update of the evidence. Nutrients 11, 1840.

17. Keller A, O'Reilly EJ, Malik V et al. (2019) Substitution of sugar-sweetened beverages for other beverages and the risk of developing coronary heart disease: results from the Harvard Pooling Project of Diet and Coronary Disease. Prev Med 131, 105970.

18. Imamura F, Schulze MB, Sharp SJ et al. (2019) Estimated substitution of tea or coffee for sugar-sweetened beverages was associated with lower type 2 diabetes incidence in casecohort analysis across 8 European countries in the EPICInterAct study. J Nutr 149, 1985-1993.

19. Beulens JW, Monninkhof EM, Verschuren WM et al. (2010) Cohort profile: the EPIC-NL study. Int J Epidemiol 39, 1170-1178.

20. Ocke MC, Bueno-de-Mesquita HB, Goddijn HE et al. (1997) The Dutch EPIC food frequency questionnaire. I. Description of the questionnaire, relative validity, reproducibility for food groups. Int J Epidemiol 26, Suppl. 1, S37-S48.

21. Dutch Food composition Database (2019) NEVO online version 2019/6.0. National Institute for public Health and the Environment (RIVM). https://nevo-online.rivm. nl/ProductenZoeken.aspx (accessed October 2020).

22. Beulens JWJ, Monninkhof EM, Verschuren WMM et al. (2010) Cohort profile: the EPIC-NL study. Int J Epidemiol 39, $1170-1178$.

23. Sluijs I, van der AD, Beulens JW et al. (2010) Ascertainment and verification of diabetes in the EPIC-NL study. Neth J Med 68, 333-339.

24. Pols MA, Peeters PH, Ocke MC et al. (1997) Estimation of reproducibility, relative validity of the questions included in the EPIC Physical Activity Questionnaire. Int J Epidemiol 26, Suppl. 1, S181-S189.

25. Wareham NJ, Jakes RW, Rennie KL et al. (2003) Validity and repeatability of a simple index derived from the short physical activity questionnaire used in the European Prospective Investigation into Cancer and Nutrition (EPIC) study. Public Health Nutr 6, 407-413.
26. Joosten MM, Grobbee DE, van der A DL et al. (2010) Combined effect of alcohol consumption and lifestyle behaviors on risk of type 2 diabetes. Am J Clin Nutr 91, $1777-1783$.

27. Looman M, Feskens EJ, de Rijk M et al. (2017) Development and evaluation of the Dutch Healthy Diet index 2015. Public Health Nutr 20, 2289-2299.

28. van den Brandt PA (2018) Coffee or Tea? A prospective cohort study on the associations of coffee and tea intake with overall and cause-specific mortality in men versus women. Eur J Epidemiol 33, 183-200.

29. WHO (2015) Guideline: Sugars Intake for Adults and Children. Geneva: World Health Organization.

30. Jiang W (2015) Dietary flavonoids intake and the risk of coronary heart disease: a dose-response meta-analysis of 15 prospective studies. Thromb Res 135, 459-463.

31. Hertog MG, Feskens EJ, Hollman PC et al. (1993) Dietary antioxidant flavonoids and risk of coronary heart disease: the Zutphen Elderly Study. Lancet 342, 1007-1011.

32. Hertog MG, Kromhout D, Aravanis C et al. (1995) Flavonoid intake and long-term risk of coronary heart disease and cancer in the seven countries study. Arch Intern Med 155, 381-386.

33. Xu H, Luo J, Huang J et al. (2018) Flavonoids intake and risk of type 2 diabetes mellitus: a meta-analysis of prospective cohort studies. Medicine 97, e0686.

34. Liu YJ, Zhan J, Liu XL et al. (2014) Dietary flavonoids intake and risk of type 2 diabetes: a meta-analysis of prospective cohort studies. Clin Nutr 33, 59-63.

35. Sluijs I, van der Schouw YT, van der A DL et al. (2010) Carbohydrate quantity and quality and risk of type 2 diabetes in the European Prospective Investigation into Cancer and Nutrition-Netherlands (EPIC-NL) study. Am J Clin Nutr 92, 905-911.

36. Salmeron J, Ascherio A, Rimm EB et al. (1997) Dietary fiber, glycemic load, and risk of NIDDM in men. Diabetes Care $\mathbf{2 0}$, 545-550.

37. Salmeron J, Manson JE, Stampfer MJ et al. (1997) Dietary fiber, glycemic load, and risk of non-insulin-dependent diabetes mellitus in women. JAMA 277, 472-477. 